\title{
Correction to: First Description of the First Crabs of Thalamita Chaptalii (Audouin, 1826) (Crustacea: Brachyura: Portunidae) from the Saudi Arabian Red Sea
}

\author{
Indra Effendy ${ }^{1} \cdot$ Anand A. J. Kumar ${ }^{1} \cdot$ Mohsen M. El-Sherbiny ${ }^{1,2}$ \\ Published online: 7 March 2022 \\ (c) Springer Nature Switzerland AG 2022
}

\section{Correction to: Thalassas: An International Journal of Marine Sciences https://doi.org/10.1007/s41208-021-00382-5}

The original article has been corrected in the acknowledgment section "grant no. DF-xxx-150-1441 with RG-1-15035 " should be "grant no. RG-1-150-35".

Publisher's Note Springer Nature remains neutral with regard to jurisdictional claims in published maps and institutional affiliations.

The original article can be found online at https://doi.org/10.1007/ s41208-021-00382-5.

Mohsen M. El-Sherbiny

ooomar@kau.edu.sa

1 Department of Marine Biology, Faculty of Marine Science, King Abdulaziz University, Jeddah 21589, Saudi Arabia

2 Department of Marine Sciences, Faculty of Science, Suez Canal University, Ismailia 41522, Egypt 